\title{
ANÁLISE DAS PRÁTICAS DE GESTÃO AMBIENTAL EM PROPRIEDADES RURAIS DO MUNICÍPIO DE SANTA MARGARIDA DO SUL-RS
}

\author{
Karen de Oliveira ${ }^{1}$, Ana Julia Teixeira Senna ${ }^{2}$
}

1. Universidade Federal do Pampa - UNIPAMPA, Graduada em Bacharelado em Gestão Ambiental pela Universidade Federal do Pampa, campus São Gabriel. karenoliveira.ga@gmail.com

2. Universidade Federal do Pampa - UNIPAMPA, Engenharia Agrícola, Mestre e Doutora em Agronegócios. Atualmente é professora Adjunta da Universidade Federal do Pampa, Campus São Gabriel. Atua nas áreas de gestão ambiental em agronegócios, economia rural e marketing ambiental. anasenna@unipampa.edu.br

http://dx.doi.org/10.5902/223611705571

\section{RESUMO}

O homem, na busca da sobrevivência, sempre afetou o ambiente natural. As transformações ambientais foram se intensificando com o advento da industrialização nas cidades e a introdução da mecanização agrícola na área rural. As atividades desenvolvidas na produção agropecuária, se não forem bem manejadas, podem interferir no equilíbrio ambiental e, portanto, na sustentabilidade do campo. Esta pesquisa tem como objetivo caracterizar as práticas de gestão ambiental adotadas em propriedades rurais localizadas no município de Santa Margarida do Sul. Inicialmente, foi feito um levantamento bibliográfico sobre gestão ambiental, extensão rural e sustentabilidade. Posteriormente, foi elaborado um roteiro de entrevistas, articulado com o referencial teórico, direcionado aos produtores rurais. Na sequência, foram entrevistados treze produtores. Após a análise dos dados, constatou-se que a maioria dos produtores se preocupa com a gestão ambiental rural, porém, alguns ainda não a introduziram em suas propriedades, por isso, verificou-se a importância da implantação de ações extensionistas e de educação ambiental, direcionados aos produtores rurais.

Palavras-chave: Gestão Ambiental Rural. Educação Ambiental. Sustentabilidade.

\section{ABSTRACT}

Man's quest for survival has always affected the natural environment. Environmental transformations got increasingly intense with the advent of industrialization in towns and the introduction of agricultural mechanization in the rural areas. The activities involving agricultural and livestock production, if not managed properly, could affect environmental stability and, therefore, interfere with sustainability at farm level. The objective of this research is to characterize the environmental management practices common in rural holdings located in the municipality of Santa Margarida do Sul. Initially, a bibliographic survey on environmental management, rural extension and sustainability was conducted. Afterwards, an interview itinerary was set up, articulated with theoretical references, geared towards rural producers. Data analysis showed that most rural producers are concerned about rural environmental management, however, some of them have not yet adopted it on their holdings, that is why it was ascertained 
Rev. Elet. em Gestão, Educação e Tecnologia Ambiental (e-ISSN: 2236-1170)

that it is utterly important to implement environment education and extension initiatives directed towards rural producers.

Key words: Rural Environmental Management. Environmental Education. Sustainability.

\section{INTRODUÇÃO}

A atuação do homem na busca da sobrevivência sempre afetou o ambiente natural. As transformações ambientais foram se intensificando com o advento da industrialização nas cidades e a introdução da mecanização agrícola na área rural.

Com as mudanças nos hábitos e nas necessidades de consumo, a sociedade humana passou a usar de forma intensiva os recursos disponíveis. Isto gerou danos em diferentes escalas e de forma crescente, tais como a redução da capacidade do solo para a produção de alimentos e a destruição de ecossistemas importantes para o equilíbrio ambiental e a sustentabilidade da vida.

A zona rural apresenta diversas fontes potenciais de geração de resíduos sólidos. Além do lixo domiciliar, uma propriedade rural, dependendo das atividades realizadas em suas dependências, pode gerar também resíduos da construção civil, resíduos agrícolas diversos, como embalagens de agrotóxicos e fertilizantes, esterco de animais e resíduos de serviços veterinários, se houver criação intensiva (OLIVEIRA e FEICHAS, 2007).

Uma das formas de orientar a população rural quanto à adoção de métodos e técnicas menos impactantes ao meio ambiente é através de ações extensionistas, como visita as propriedades rurais, realização de dias de campo com apresentação de unidades demonstrativas de métodos e técnicas, dentre outros.

Neste sentido, a extensão rural consiste em um serviço público de caráter técnico prestado às famílias de pequenos e médios produtores rurais, por profissionais devidamente qualificados, visando o aumento da produtividade e da melhoria de vida da família rural, impactando o mínimo possível o meio ambiente (EMATER/RS, 2010).

A educação ambiental pode ser considerada uma ação que busca proporcionar à comunidade o acesso à informação, disseminando diversos aspectos relacionados às questões ambientais. Ações nesse sentido são realizadas por organizações públicas, comunidades locais, ONGs e Universidades.

Segundo Carvalho (2001), a educação ambiental vem sendo incorporada como uma prática inovadora em diferentes níveis, destacando-se tanto como objeto de políticas públicas de educação e de meio ambiente em níveis regional e nacional, como mediação educativa, por um amplo conjunto de práticas de desenvolvimento social.

No contexto desta pesquisa, gestão ambiental diz respeito às práticas adotadas na busca da sustentabilidade. A gestão ambiental pode ser entendida como um processo que incorpora um conjunto de instrumentos (legais, tecnológicos, educativos, científicos), visando ordenar as atividades humanas para que originem o menor impacto negativo possível sobre o meio. Esta sistemática consiste na escolha das melhores técnicas, no cumprimento da legislação e na alocação eficaz de recursos humanos e financeiros (DE BRUNS, 2006).

Quando se analisa a gestão ambiental rural, deve-se levar em conta que as primeiras preocupações ambientais no Brasil, surgiram a partir da institucionalização ambiental e hídrica, com a edição dos Decretos Leis que instituíram o primeiro Código Florestal (Decreto Lei no 23.793, 
de 23 de janeiro de 1934) e o Código das Águas, através do Decreto Lei no 24.643, de 10 de julho de 1934 (FLORIANO, 2007).

Conforme a Resolução 0001/86 do Conselho Nacional do Meio Ambiente - CONAMA, qualquer alteração das propriedades físicas, químicas ou biológicas do meio ambiente, por qualquer outra forma de matéria ou energia, lançados na água, no solo ou na atmosfera, acaba por interferir direta ou indiretamente, nas condições de segurança, saúde e bem estar da população humana, da fauna, flora e dos recursos naturais.

Quanto à área rural, a poluição hídrica e a dos solos, são as formas de poluição mais comuns no meio rural. As atividades agrícolas e pecuárias, quando não bem manejadas, constituem riscos ao equilíbrio ambiental e, portanto, à sustentabilidade da vida no campo.

Sendo assim, o objetivo desta pesquisa é analisar as práticas de gestão ambiental adotadas nas propriedades rurais do município de Santa Margarida do Sul - RS. Para tanto, está estruturada da seguinte forma: primeiramente, foi feito uma revisão bibliográfica sobre a gestão ambiental, extensão rural e sustentabilidade. Posteriormente, foi construído um roteiro de entrevistas, articulado com o referencial teórico. Na sequencia, foram entrevistados treze produtores rurais de Santa Margarida do Sul, RS. Por fim, são apresentados os resultados e discussões e as conclusões.

\section{METODOLOGIA}

Inicialmente foi feito um levantamento bibliográfico sobre gestão ambiental, extensão rural e sustentabilidade. Posteriormente, foi elaborado um roteiro de entrevistas, articulado com o referencial teórico.

Na sequência, foram entrevistados treze produtores rurais de Santa Margarida do Sul, sendo selecionados aleatoriamente. As entrevistas ocorreram na Secretaria de Agricultura e Meio Ambiente do município de Santa Margarida do Sul (RS), nos meses de setembro e outubro de 2010.

Após, foi feita a análise descritiva dos dados coletados. Os resultados foram sumarizados através de gráficos, que apresentam uma síntese das respostas obtidas através das entrevistas. Os produtores entrevistados foram codificados, para preservar a identidade dos respondentes, conforme a Tabela 1. 
Rev. Elet. em Gestão, Educação e Tecnologia Ambiental (e-ISSN: 2236-1170)

\begin{tabular}{c|c}
\hline $\begin{array}{c}\text { PRODUTOR } \\
\text { ENTREVISTADO }\end{array}$ & CODIFICAÇÃO \\
\hline $1^{\circ}$ produtor & P1 \\
\hline $2^{\circ}$ produtor & P2 \\
\hline $3^{\circ}$ produtor & P3 \\
\hline $4^{\circ}$ produtor & P4 \\
\hline $5^{\circ}$ produtor & P5 \\
\hline $6^{\circ}$ produtor & P6 \\
\hline $7^{\circ}$ produtor & P7 \\
\hline $8^{\circ}$ produtor & P8 \\
\hline $9^{\circ}$ produtor & P9 \\
\hline $10^{\circ}$ produtor & P10 \\
\hline $11^{\circ}$ produtor & $\mathbf{P 1 1}$ \\
\hline $12^{\circ}$ produtor & $\mathbf{P 1 2}$ \\
\hline $13^{\circ}$ produtor & $\mathbf{P 1 3}$ \\
\hline
\end{tabular}

Tabela 1 - Codificação dos produtores rurais entrevistados Fonte: Autora, 2010

\section{RESULTADOS E DISCUSSÃO}

Os resultados serão apresentados conforme a sequência do roteiro de entrevistas que foi composto por dois grupos de questões. O Grupo 1 consistiu na caracterização da propriedade rural e o Grupo 2 abordou a atitude do produtor rural quanto as práticas adotadas na busca da sustentabilidade. A seguir serão descritos e analisados os resultados obtidos.

\section{Caracterizações da propriedade rural}

O primeiro tema tratado no roteiro de entrevistas, aplicado aos produtores rurais de Santa Margarida do Sul, foi à caracterização da propriedade rural. A Figura1 apresenta uma síntese dos resultados. 


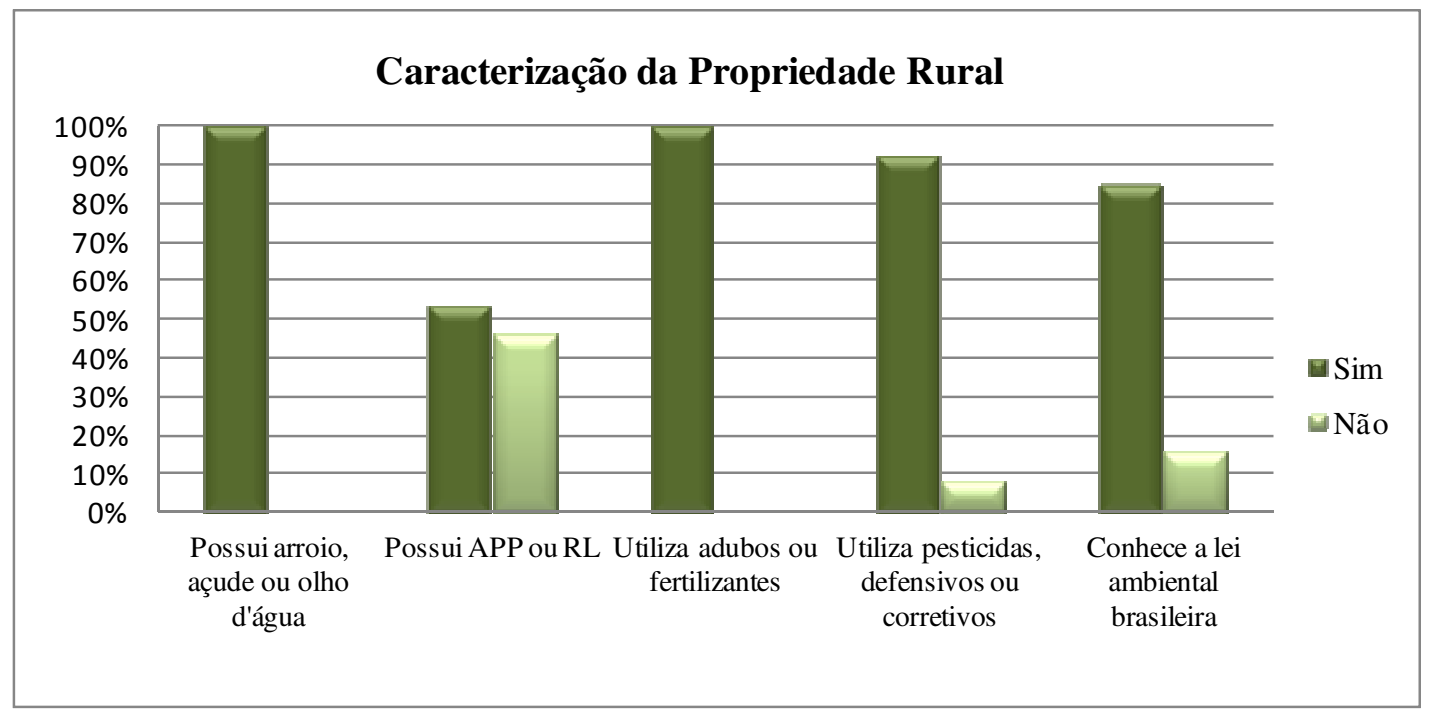

Figura 1 - Caracterização da propriedade rural Fonte: Dados coletados, 2010.

Quanto à área das propriedades rurais, P1 possui área equivalente a 1000 ha, P2 e P6 possuem cerca de 450 ha, enquanto P4, P5 E P7 possuem 300 ha. Dois produtores rurais (P12 e P13) possuem área de 150, P9 possui área de 75 ha, enquanto P3, P8, P10, P11 possuem área inferior a 50 ha.

Todos os produtores entrevistados possuem pelo menos um arroio, açude ou olho d'água na propriedade (Figura 1). Isto se justifica, principalmente, pelo fato de serem propriedades com áreas extensas, que possuem agricultura e necessitam de irrigação.

Entre as propriedades investigadas, $54 \%$ possuem reserva legal $(\mathrm{RL})$ ou área de preservação permanente (APP) e $46 \%$ não possuem. Um dos produtores entrevistados (P4), que possui uma área de preservação permanente em sua propriedade relatou que deixa uma área destinada à preservação, pois esta é inadequada para o cultivo agrícola. Dos $46 \%$ que não possuem APP ou RL em suas propriedades, P1 justificou que adquiriu a propriedade recentemente, mas que pretende atender essa exigência ambiental. Os produtores restantes ainda não têm essa preocupação, e desconhecem o fato de que ao adquirir uma propriedade rural sem reserva legal, estarão obrigados objetivamente ao pagamento desse débito ambiental.

Conforme mostra a Figura 1, todos os produtores entrevistados utilizam adubos ou fertilizantes na lavoura. Apenas $8 \%$ não utilizam pesticidas, defensivos ou corretivos, pois estão preocupados com a minimização dos riscos à saúde humana e com os impactos ambientais na água e no solo.

Dos produtores entrevistados, $85 \%$ disseram conhecer a lei ambiental brasileira. Destes, P1, P6 e P11 relataram que conhecem a lei ambiental, porém, destacaram no momento da entrevista que seus conhecimentos sobre o tema são restritos. Já P2 afirmou ter conhecimento, mas salientou que não aplica todas as leis, pois se aplicasse teria uma redução de produtividade e rentabilidade. P9 e P12 desconhecem a lei ambiental brasileira. Contudo, pode-se destacar a importância da legislação ambiental no que tange as propriedades rurais a fim de percebê-la como instrumento de controle ambiental e os benefícios gerados a partir do cumprimento da mesma para a propriedade. 


\section{Práticas Sustentáveis}

A Figura 2 apresenta uma síntese das respostas sobre as práticas sustentáveis adotadas nas propriedades rurais investigadas.

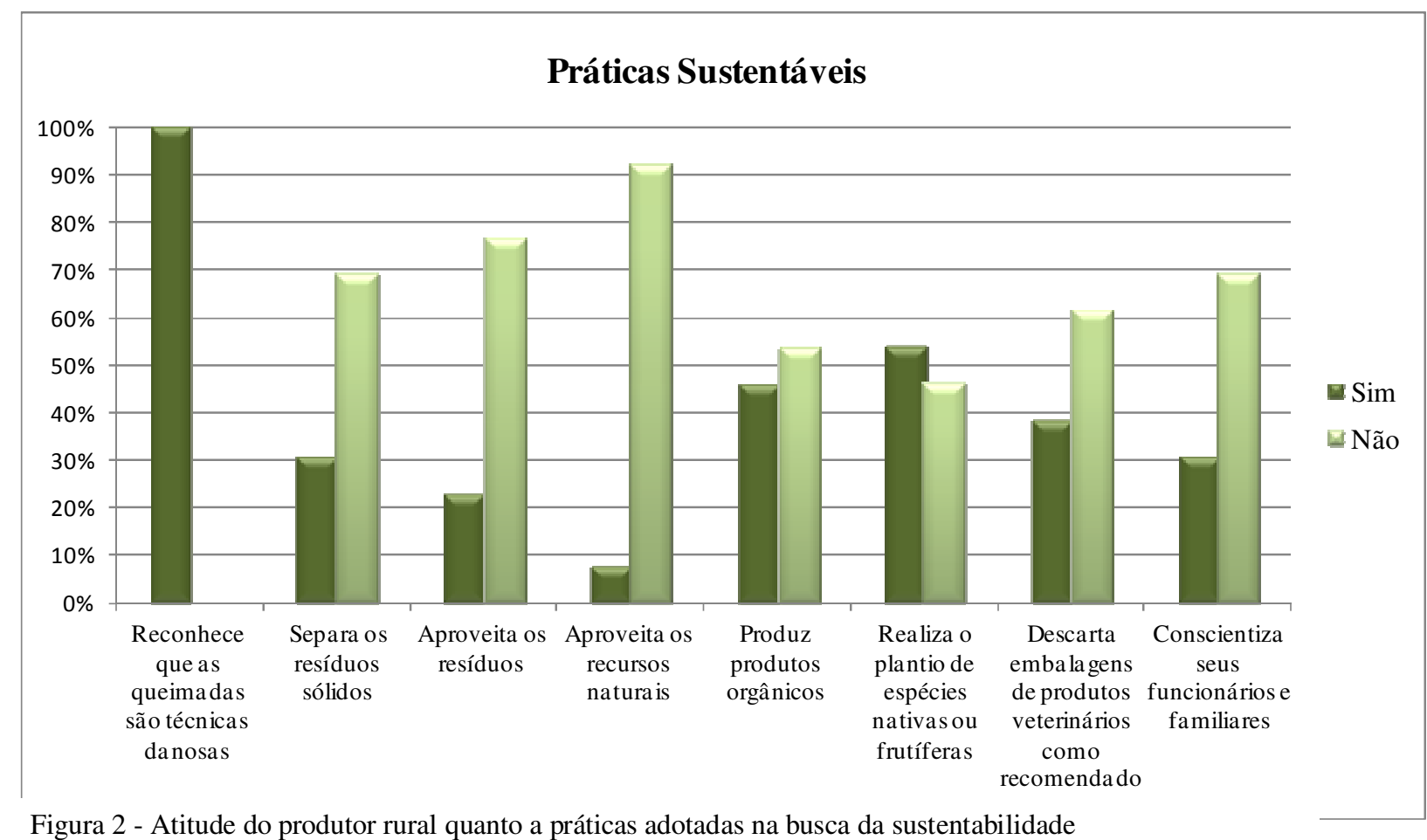

Figura 2 - Atitude do produtor rural quanto a práticas adotadas na busca da sustentabilidade Fonte: Dados coletados, 2010.

No que diz respeito à atitude e ao comportamento do produtor rural quanto às práticas adotadas na busca da sustentabilidade, todos os entrevistados reconhecem que o uso das queimadas nas propriedades é uma técnica de manejo danosa aos sistemas agropecuários ou florestais (Figura 2). Isto ocorre porque as queimadas provocam a perda da fertilidade do solo e a poluição atmosférica. Todos os respondentes afirmaram que não utilizam esta técnica. Destes, P4 ainda salientou que o uso de queimadas além de ser prejudicial ao meio ambiente é uma prática proibida. P8 relatou que não realiza queimadas, e tem consciência de que o uso contínuo do fogo leva à exposição do solo, o que pode acentuar a compactação e provocar a erosão.

A questão do gerenciamento dos resíduos sólidos rurais é pouco estudada quando comparado a gestão dos resíduos urbanos. No entanto, os tipos de resíduos gerados numa propriedade rural são tão relevantes e impactantes quanto os urbanos.

Conforme mostra a Figura 2, 31\% dos produtores entrevistados afirmaram que realizam a separação dos resíduos sólidos de suas propriedades. P2 relatou que busca conscientizar seus familiares quanto à correta separação dos resíduos, mas este procedimento não é eficaz, mesmo tendo em sua residência dois coletores (resíduos orgânicos e secos). P4 relatou que separa os 
Rev. Elet. em Gestão, Educação e Tecnologia Ambiental (e-ISSN: 2236-1170)

plásticos, papéis, vidros e outros materiais, porém acredita não ser tão eficiente, pois não existe coleta seletiva no Município de Santa Margarida do Sul. P5 afirmou que enterra os resíduos de sua propriedade. P9 afirmou que separa parcialmente os resíduos, como latas e vidros, e os plásticos são queimados, desconhecendo que a incineração de materiais como plásticos do tipo PVC, podem provocar a formação de furanos e dioxinas, compostos altamente tóxicos e cancerígenos. P12 afirmou que separa apenas plástico e papéis.

Diante destes achados, pode-se dizer que os resíduos oriundos da zona rural têm recebido pouca atenção dos órgãos governamentais. Isto ocorre, principalmente, porque as propriedades rurais estão em sua maioria distantes geograficamente e, assim, os resíduos gerados ficam pulverizados e, muitas vezes, parecem ser em menor quantidade que nas cidades.

Quanto à reciclagem, venda ou compostagem, $23 \%$ dos produtores entrevistados relataram que aproveitam os resíduos como, cascas de frutas, legumes e erva mate, como composto orgânico para a horta. Os demais produtores, 77\%, não aproveitam os resíduos.

Quanto à questão da água da chuva, energia solar, cataventos e outros recursos naturais serem aproveitados para o suprimento ou geração de energia, $8 \%$ dos produtores entrevistados relataram que aproveitam a água da chuva, principalmente no verão, como forma de evitar a escassez da água. Já $92 \%$ dos entrevistados não aproveitam os recursos naturais com este fim (Figura 2).

Dos produtores entrevistados, $46 \%$ relataram que produzem algum tipo de produto orgânico livre de agrotóxicos em suas propriedades, especialmente, aqueles produzidos na horta, como verduras e legumes, para o consumo próprio. P8 e P11 relataram que seus produtos orgânicos servem para o consumo da família, mas também são comercializados. $54 \%$ não produzem produtos orgânicos, sendo que a mesma porcentagem de entrevistados afirmou que realiza o plantio de espécies nativas ou frutíferas em suas propriedades, favorecendo assim a biodiversidade no local.

Em relação ao armazenamento e ao descarte das embalagens vazias de medicamentos e produtos veterinários, os produtores que possuem criação de animais em suas propriedades, que correspondem a $38 \%$ dos entrevistados, relataram que as embalagens de medicamentos são descartadas juntamente com os demais resíduos. Portanto, ficou evidente que os respondentes desconhecem o fato do material veterinário representar um risco para o meio ambiente, para as pessoas e animais que tem contato com estes produtos. Os entrevistados demonstraram dar uma melhor disposição final às embalagens de agrotóxicos do que ao material veterinário.

O conhecimento das razões pelas quais se deve agir de determinada maneira motiva o indivíduo a fazer escolhas responsáveis do ponto de vista ambiental. 31\% dos produtores entrevistados relataram que incentivam a conscientização de seus funcionários e familiares sobre a conservação e preservação do meio ambiente, enquanto $69 \%$ demonstraram pouca preocupação com essa questão. P2 relatou que tenta conscientizar seus familiares e funcionários, porém afirmou não ter sucesso. P4 e P5 relataram que as empresas onde os produtores compram os agrotóxicos ou fertilizantes, fazem reuniões e transmitem as informações para os produtores e funcionários, orientando-os sobre as questões ambientais, porém, não são todos produtores que participam. P8 relatou que conscientiza sua família a utilizar os recursos disponíveis e ao mesmo tempo mantê-los e conservá-los, para garantir que as gerações futuras encontrem um ambiente compatível com as suas necessidades.

\section{CONCLUSÕES}


A pesquisa permitiu identificar a inexistência de um sistema de gestão ambiental eficaz nas propriedades rurais entrevistadas em Santa Margarida do Sul, RS. A maioria dos produtores declarou que se preocupa com o meio ambiente e seus recursos, porém, percebe-se que eles necessitam de um melhor esclarecimento sobre gestão de resíduos, manejo de solos e determinações da legislação ambiental.

Nas propriedades investigadas, ficou evidenciado que a extensão territorial não influencia na adoção da gestão ambiental e na preocupação dos produtores com a sustentabilidade.

Em relação à gestão ambiental nas propriedades rurais, verificou-se que poucos produtores realizam a coleta seletiva dos resíduos sólidos de suas propriedades. Isto, sem dúvida, destaca a necessidade de capacitação dos profissionais da área e a implantação de programas de educação ambiental direcionado aos produtores rurais e aos seus colaboradores e familiares, visando à implantação e melhoria do processo de gestão ambiental na área rural. A gestão adequada dos recursos naturais, dos insumos e de seus resíduos leva a maior produtividade e lucratividade dos sistemas de produção. A adoção das melhores práticas nas propriedades rurais é fundamental para viabilizar sistemas produtivos mais sustentáveis.

Os produtores rurais devem trabalhar, seja individual ou coletivamente, para produzirem alimentos com o mínimo de impacto ao meio ambiente. As reservas legais e as áreas de preservação permanentes são instrumentos imprescindíveis na gestão ambiental local e regional.

A população de Santa Margarida do Sul está concentrada na área rural. Tal município foi emancipado há cerca de dezesseis anos e se encontra em processo de desenvolvimento. Os recursos financeiros são limitados, o que impossibilita o deslocamento dos técnicos para o atendimento e a orientação aos produtores na área rural. Isto interferiu na realização das entrevistas com os produtores rurais e, sem dúvida, também poderá interferir no processo de educação ambiental e nas atividades de extensão rural.

Para a maior conscientização das comunidades rurais é preciso sistematizar ações continuas e permanentes de educação ambiental. Essa é uma ferramenta fundamental para o processo de mudança de percepção dos produtores sobre os impactos ambientais das atividades rurais.

Enfim, a extensão rural não deve restringir-se à assessoria técnica, mas expandir-se para a proposição e posterior acompanhamento de políticas públicas que estimulem o desenvolvimento rural sustentável. As ações devem ser direcionadas a atender às necessidades demandadas pela sociedade, aliadas as técnicas menos impactantes ao meio ambiente que visem à preservação ambiental. Assim, espera-se que a presente pesquisa sirva como ferramenta para os gestores, públicos e privados, que são os tomadores de decisão e responsáveis pelo planejamento da área rural.

\section{REFERÊNCIAS BIBLIOGRÁFICAS}

CARVALHO, I.C.M. Qual educação ambiental? Elementos para um debate sobre educação ambiental População e Extensão Rural. Agroecologia e Desenvolvimento Rural Sustentável. Porto Alegre, v.2, n.2, abr./jun.2001. Disponível em: <http://www.agroecologia.inf.br/biblioteca/educacao\%20ambiental.pdf >. Acesso em: 23 mai. 2012. 
CONAMA - CONSELHO NACIONAL DO MEIO AMBIENTE. Resolução no 1, de 23 de janeiro de 1986. Disponível em: <http://www.mma.gov.br/port/conama/res/res86/res0186.html>. Acesso em: 19 mai. 2012.

DE BRUNS, G. B. Afinal, o que é gestão ambiental? Disponível em: http://ambientes.ambientebrasil.com.br/gestao/artigos/afinal\%2C_o_que_e_gestao_ambiental \%3F.html. Acesso em: 22 mai. 2012.

EMATER/RS - Associação Riograndense de Empreendimentos de Assistência Técnica e Extensão Rural. Disponível em: <www.emater.tche.br>. Acesso em: 29 abr. 2012.

FLORIANO, E. P. Políticas de gestão ambiental, 3ed. Santa Maria: UFSM-DCF, 2007. 111 p. anexos. Disponível em: <http://www.ufsm.br/dcfl/seriestecnicas/serie7.pdf>. Acesso em: 19 mai. 2012.

OLIVEIRA, K. V.; FEICHAS, S. A. Q. Subsídios a proposta de gerenciamento de resíduos sólidos em área rural: caso de Encruzilhada do Sul - RS. XI ENGEMA - Encontro Nacional sobre Gestão Empresarial e Meio Ambiente. Curitiba, 2007. Disponível em: <http://engema.up.edu.br/arquivos/engema/pdf/PAP0330.pdf>. Acesso em: 25 mai. 2012. 